\title{
SMILE: Smart Monitoring Intelligent Learning engine. An Ontology-based Context-aware system for supporting patients subjected to severe Emergencies
}

\author{
Malak Khareis*, Iyad Zaarour*, and Hamid Mcheick** \\ **Department of Computer Science and Mathematics, \\ University of Quebec at Chicoutimi (UQAC), Quebec, Canada \\ *Department of Computer Science, Lebanese University, Lebanon \\ E-mail:**hamid_mcheick@uqac.ca, \\ E-mail: *malakkhreis@outlook.com, \\ E-mail:*iyad.zaarour@gmail.com \\ **Corresponding author
}

\begin{abstract}
Remote healthcare have made a revolution in the healthcare domain. However, an important problem this field is facing is supporting patients who are subjected to severe emergencies (as heart attacks) to be both monitored and protected while being at home. In this paper we present a a conceptual framework with the main objectives of:1) emergency handling through monitoring patients, detecting emergencies and insuring fast emergency responses, 2) preventing an emergency from happening in the first place through protecting patients by organizing their lifestyles and habits. To achieve these objectives we propose a layered middleware. Our context model combines two modelling methods: probabilistic modeling to capture uncertain information and ontology to ease knowledge sharing and reuse. In addition, our system uses a two-level reasoning approach (ontology-based reasoning and Bayesian-based reasoning) to manage both certain and uncertain contextual parameters in an adaptive manner. Bayesian network is learned from ontology. Moreover, to insure a more sophisticated decision making for service presentation, Influence Diagram and Analytic Hierarchy Process are used along with regular probabilistic rules (Confidence Level) and basic semantic logic rules.
\end{abstract}

Keywords: Healthcare, Remote Systems, Ontology design, Probabilistic reasoning and Uncertainty, Middleware, Intelligent systems, Pervasive computing.

Biographical notes: Hamid Mcheick is currently an associate professor in computer science department at the University of Quebec At Chicoutimi (UQAC), Canada. He holds a master degree and PhD. in software engineering and distributed system from Montreal University, Canada. Professor Mcheick is interested in software development and architecture for enterprise applications as well as in separation of concerns (component, services, aspect, etc.). His research is supported by many research grants he has received from the Canadian government, University of Montreal, CRIM (Centre de Recherche informatique de Montreal), University of UQAM, and University of UQAC.

Malak Khreis is presently a PhD student in Management Information Systems at the Doctoral School of Law, Political, Administrative, and Economic Sciences of the Lebanese University. As the first among her classes, she earned her Man agement Information Systems degree from the Lebanese University - Faculty of Business Administration and Economi c Sciences in 2012, and completed her traineeship at the Lebanese Central Bank. She received her Research Master De gree in Information and Decision Support Systems from the Lebanese University - Faculty of Sciences in 2014. Malak' s research spans a variety of areas including Emotion Awareness, Ambient Intelligence and Context Awareness with re gards to Context Modelling, Context Reasoning, and Decision-Making techniques in context

aware systems. Mainly, her current PhD topic is focused on how to benefit from the latter psychological and computing concepts to boost the productivity of human resources in knowledge-based business enterprises.

Iyad Zaarour is an Assistant Professor in Faculty of Economical sciences and Management At Lebanese University, his research efforts on Machine Learning, Probabilistic reasoning, and Data Mining, with latest study on causality in the Framework of Bayesian Network Formalism and Epidemiology Discipline, he has an adjacent association with Doctoral School (EDST) of Faculty of science at Lebanese University, and a close collaboration with The Laboratory of Biomedical Department of Islamic University in Partnership with (GREAH) Laboratory of Le Havre University France. He is associated with the Laboratory (LITIS- EA 4108) at Rouen University-France where he got his Ph.D in Computer Science since 2004. His applications interest consists of the handwriting, neurology, social Networks, ethics, medicine, motor control and Parkinson Disease. He is one of the directors of the Transcendental Scientific Realism institute in Lebanon. 


\section{Introduction}

The main aim of all sciences is to serve humanity. There is no doubt that health, in its wide meaning, is the most precious gift to the human race and healthcare is one of the noblest scientific fields that are rapidly witnessing major developments in the aim of giving human beings more hope in life. Although traditional medication and healthcare tools have proved to be very beneficial, but they seem to be insufficient in some cases. Taking into consideration, for example, the case of patients who are subjected to severe emergencies as heart strokes, monitoring patients at the hospital and giving them the right treatments could certainly help in reducing the risk of having an emergency, but it may on the other hand result serious psychological problems due to having a stressful life routine, which would worsen the situation. Consequently, researchers are untiringly trying to come with better solutions to assist such patients while being outside the clinical walls using what is so-called: remote healthcare.

As researchers are revealing, context aware pervasive systems seems to be a very adequate solution. A system is contextaware if it uses context to provide relevant information and/or services to the user, where relevancy depends on the user's task [9]. Additionally, body sensors are emerging as a light alternative to heavy health monitoring tools. In the matter of fact, body sensors and other physical and virtual sensors can collect important data about the patients and their environment to allow presenting remote healthcare services while the patients are in the people's most familiar and comfortable environment: their home. Consequently, we do believe that traditional healthcare tools and the latest computing technologies form a perfect combination.

In this work, we present an ontology-based context aware framework for smart remote healthcare. The system's main objective is presenting two types of healthcare services: emergency handling and emergency prevention. In these two functionalities lies the particularity of our proposed system since the health care services it presents are not just about regular monitoring or assistance. Above that it also aims to prevent an emergency from happening in the first place providing full healthcare services package to its users.

Heart problems are found to be not only the most severe emergency but also the leading cause of death worldwide [1], so our study is mainly focused on heart patients to find means that: (1) improve their life lifestyle to prevent heart-related emergencies from happening and (2) ease a fast detection and efficient emergency response to handle an emergency when it happens. In other words, the system's objectives are to save the users in case an emergency happens, protect them from having an emergency (as much as possible), and present its services while the users are in the people's most intimate environment, their home. We call our system SMILE, an abbreviation of: probabiliStic and Mathematical Intelligent Engine, since we design its concept with the future vision of giving patients threatened with severe emergencies a feeling of safety and protection, which indeed can have a great role in their healing process.

In this study we develop an extension for a previous work [10]. Formerly, we proposed CARE, a context aware framework for health monitoring, but only explored AHP decision making model for optimal road selection. In this work we complete our study by developing a conceptual framework for context modeling, reasoning and decision making.

This article is divided into 5 sections. In section 2 we highlight most of the key efforts reported in the literature. In section 3 we illustrate the motivational scenario. In section 4, we explain our approach's conceptual framework specifically the system architecture regarding context modeling, context reasoning and decision making techniques. Finally, in section 5 we conclude the paper and present our view of the future work.

\section{Motivation Scenario}

John, a middle-aged 40 year old man, lives alone and uses sMILE since he has high blood pressure and too high levels for the HDL cholesterol which can cause serious heart-related emergencies.

On a regular working day as John wakes up at 6 a.m, the system notifies him to be prepared for his workout time is going start in 10 minutes, then displays the workout training video on John's TV. During exercising, his heart muscles are found to be tired so the system asks John to rest. As John enters the kitchen, the system displays what are the recommended food types and their portions for breakfast on his phone, reminds him to take his medicines, and asks him to submit that he took them. Before leaving home to work, a notification appears to remind him that he must wear something to keep him warm since the weather is expected to be cold during the day hours. When he gets inside the car the sMILE shows the less congested road to take to reach work using a map screen placed in front of the John's seat. After he finishes work, John decides to go shopping. When he enters the supermarket the system displays a message containing the list of food recommended for this week. At the end of the day John gets back home and sleeps, the system plays music therapy tracks.

On another day, while John is jogging at his backyard he falls down. The system reports that the patients is having an emergency and automatically notifies a relative and sends a notification alarm to the nearest hospital. The hospital prepares specific instruments and empties a room for John. The system then assigns the nearest ambulance and sends it information concerning the best road that leads to John's house. It also provides the rescue team with information about the possible emergency and 
what types of medication John is allergic to. Finally, the ambulance reaches John and takes him to the nearest hospital by using the same criteria of traffic recognition. Figure 1 shows the system while being in action for both cases.

Figure 1 sMILE system in action
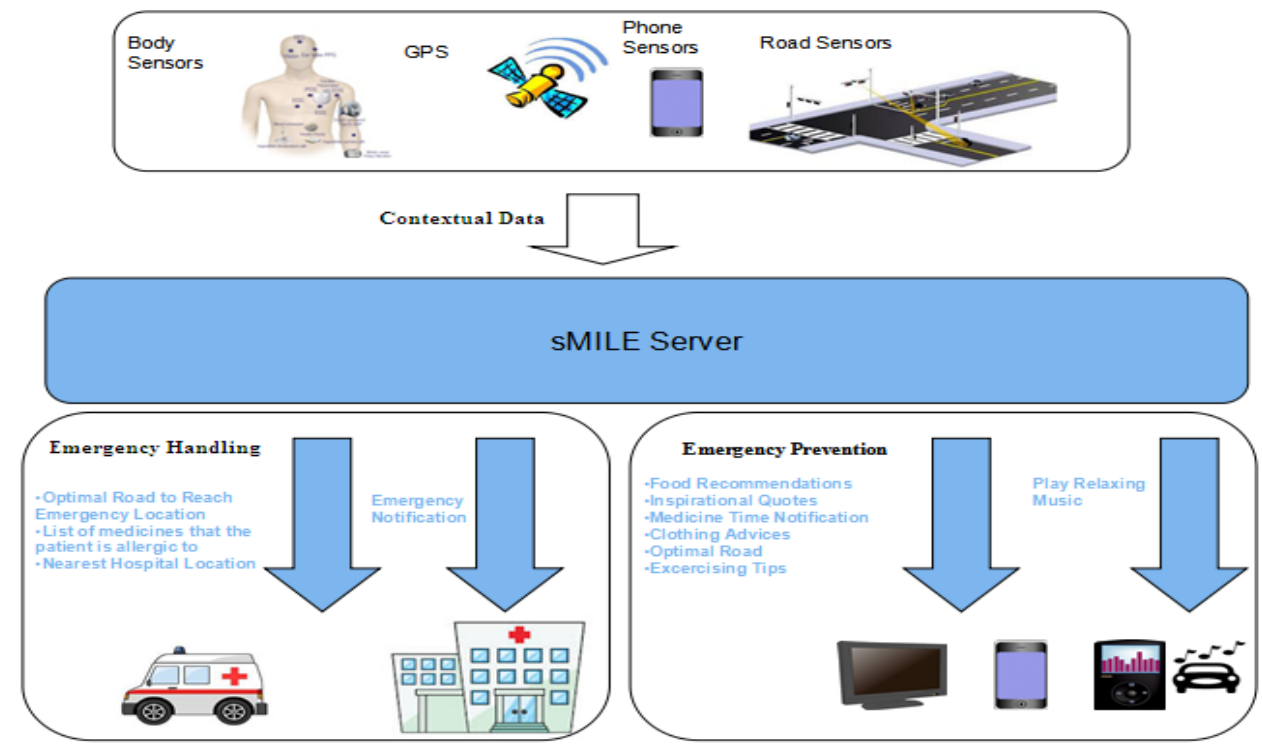

\section{Related Works}

Many researcher works have been focused on studying context awareness and demonstrating its usefulness in remote health care domain. Some of these systems deal with distant monitoring and emergency response, while others systems introduced new assistants. For example, Korhonen et Al. [2] introduced a social alarm for elderly based on wearable sensors and intelligent monitoring. In addition, Pagnelli et Al. [3] presented an ontology-based context model and a related context management system providing a configurable and extensible service-oriented framework to ease the development of applications for monitoring and handling patient chronic conditions. Likewise, Helal et Al. [4] proposed to combine Java smart phones and smart home to provide assistance for elderly patients (mobile patient care giving assistant, general reminder system, notification of events such mail delivery, water leak, etc. In the same manner, Mihailidis et Al. [5] presented an assistant that works during hand washing for adults with dementia.

\section{SMILE system}

Figure 2 depicts sMILE's system architecture. It is developed based on a middleware infrastructure which seems to be very convenient to the requirements of context-aware systems due to its ability of allowing separation of concerns, easing extensibility and simplifying the reusability of hardware [6]. The framework is separated into 3 basic layers: Context Acquisition Layer, Context Processing Layer and Service Presentation Layer. In addition, cloud technology is used for managing historical data storage. To begin with, the Context Acquisition Layer is formed of a collection of sensors responsible for acquiring various contextual data. After, the data collected is sent to the Context Processing Layer which provides a mechanism to raise the results provided by the first layer to a higher abstraction level, then saves results locally and at the history cloud which offers a significant amount of storage capabilities. The stored data is updated every 24 hours, and retrieved through both push and pull methods. Finally, processing results are sent to the Service Presentation Layer via push and pull methods. This layer mainly controls the actual reactions of the system on various events and contextual instances.

Figure 2 sMILE architecture 


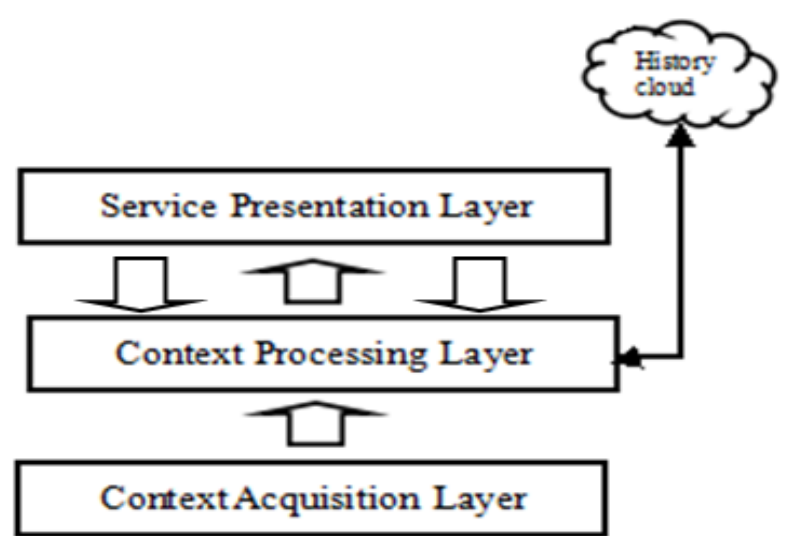

Our study is mainly interested in two layers: the Context Processing Layer and the Service Presentation Layer. Both layers will be explained in details in the upcoming sections.

\subsection{Context Processing layer}

The main function of this layer (Figure 3) is to raise the data presented by context acquisition layer to a higher abstraction level so that the system can determine, for example, whether the patient is tired through capturing some physical data like breathing rate, blood pressure and heart rate or whether the patient is sleeping by analyzing the location's noise level, lightning level and posture. To make this analysis work correctly it has two components: the Context Knowledge Base and the Reasoning Engine.

Figure 3 Components of the Context Processing Layer

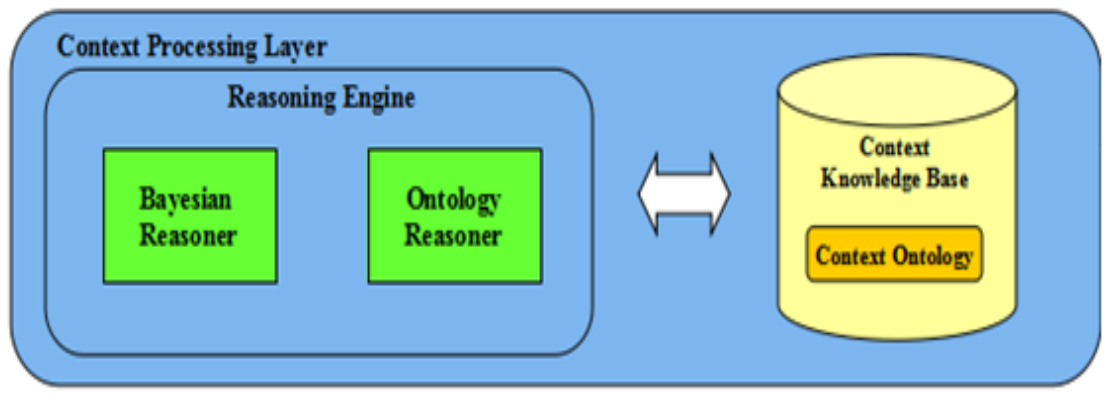

A. The context knowledge base

The Context Knowledge Base uses ontology to represent context information in a structured form. An ontology [19] is a common framework which permits sharing and reusing of data by human and machine. We have chosen since it appears to be the most expressive model that fulfills most of requirements of context aware systems [7]. SMILE's ontology model (Fig. 4) gives the system's sensors, actuators, and other computational entities a common set of concepts to interact with one another and maintain the coherence of the knowledge structure.

Basically, seven entities describe the user context in general: Person, Time, Activity, Environment, Location, CompEntity, and SimpleEvent.

It is noteworthy that recognizing the user's activities depends on a recording a combination of simple events at specific time stamps. As we will see later, the importance of the class "SimpleEvent" is highlighted by the nature of Bayesian reasoning in sMILE, which uses subclasses of SimpleEvent in order to recognize more complex context parameters, specifically those of class Activity.

In addition, we use the encoding developed by [8] to represent the probabilistic properties (i.e. probabilities and conditional probabilities) of the acquired information. For instance, consider that $\mathrm{P}$ (UserIsSleeping) $=0.6$ and $\mathrm{P}($ UserIsSleeping $\mid$ UserOnBed $)=0.8$, then these information are represented in the ontology as follows:

$<$ prob:PriorProbObj ref:ID="P(UserIsSleeping)"'>

$<$ prob:hasVariable $>$ 
$<$ rdf:value $>$ \&ont; UserIsSleeping $</$ rdf:value $>$

$</$ prob:hasVariable $>$

$<$ prob:hasProbValue $>0.6</$ prob:hasProbValue $>$

$</$ prob:PriorProbObj $>$

$<$ prob:CondProbObj rdf:ID=" $P($ UserIsSleeping $\mid$ UserOnBed $)>$

$<$ prob:hasCondition $>$

$<$ rdf:value $>$ \&ont; UserOnBed $</$ rdf:value $>$

$</$ prob:hasCondition $>$

$<$ prob:hasVariable $>$

$<$ rdf:value $>$ \&ont; UserIsSleeping $</$ rdf:value $>$

$</$ prob:hasVariable $>$

$<$ prob:hasProbValue $>0.8<$ prob:hasProbValue

$</$ prob:CondProbObj $>$

Figure 4 Layer Partial definition of the domain specific ontology

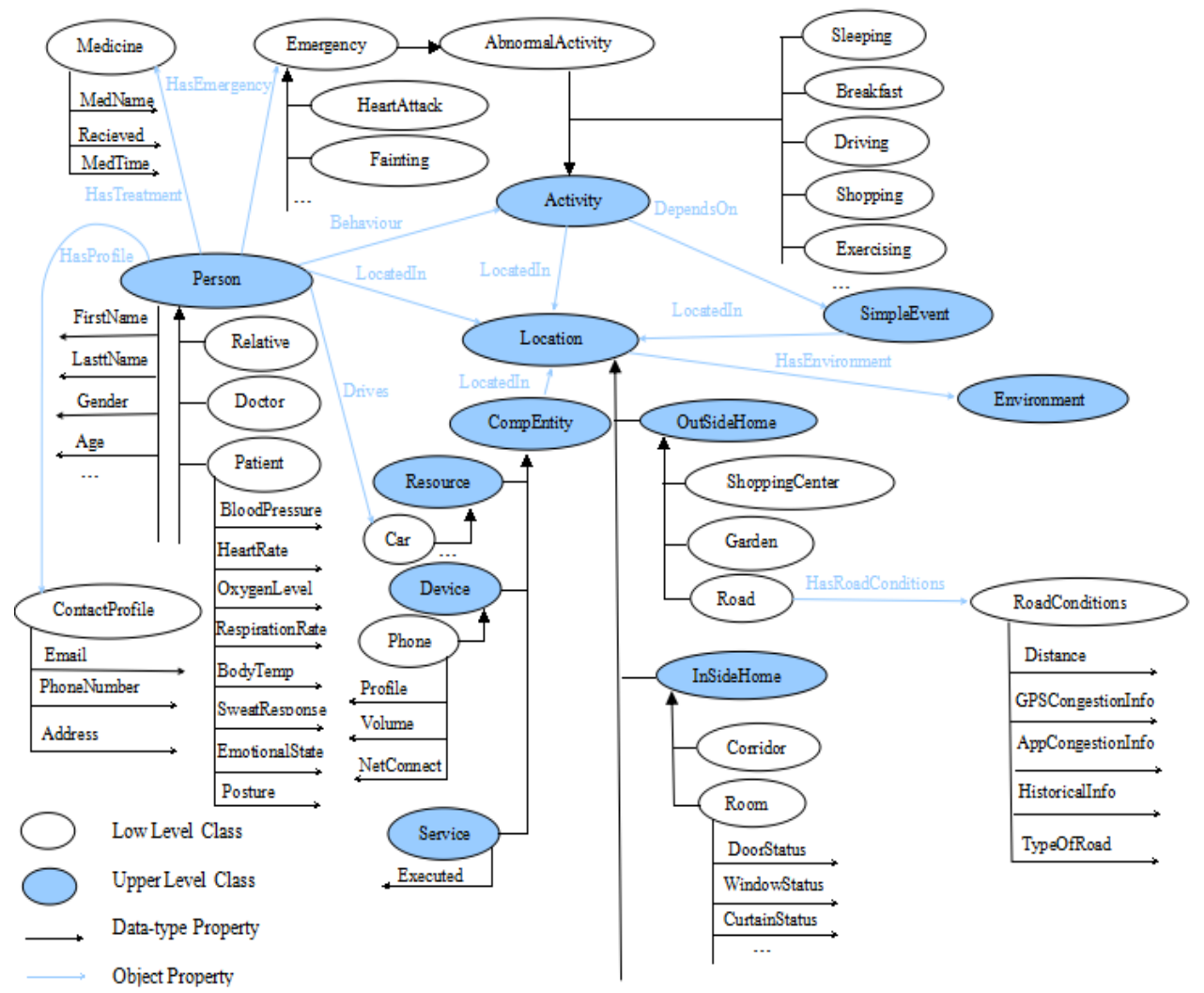

B. The context reasoning engine

The Context Reasoning engine is responsible of realizing the intelligence of the system with the main processing tasks of querying context knowledge and deducing high level context or logical context as the user's activities from low level context or physical context like posture, sweat response, breathe rate, location, movement etc... It retrieves contextual information from the context knowledge base to return an updated context model. Each type of information has a specific nature so to have more sophisticated reasoning results the Context Reasoning Engine uses two reasoning components: the Ontology reasoner and the Bayesian reasoner where each of them handles specific type of information.

The Ontology Reasoner is the first reasoning level. Mainly, it contains pre-defined rules (written in SWRL [11] language). These rules are divided into two categories. The first one simply produce instances of the class "simpleEvent" at specific time stamps. Each recognition of a new simple event changes its property "SetActive" into true, for the recognized event and false for other event that can not intersect with it( for example a person can not be standing and sitting at the same time). Example of these rules are the following:

RoomLocation(?x)^Posture(User, “LyingDown”) ^LocatedIn(User,?x) ^ SetActive(PersonLyingDown,false) $\rightarrow$

SetActive(PersonLyingDown,true $) \wedge$ SetActive(PersonSitting,false $) \wedge$ SetActive(PersonStanding,false $) \wedge$ LocatedIn(PersonLyingDown, ?x)

Copyright (C 2016 Inderscience Enterprises Ltd. 
Location(?x) $\wedge$ Environment(?y) $\wedge$ LocatedIn(User,?x $)^{\wedge}$ hasEnvironment(?x,?y) $\wedge$ Temperature(?y,?temp $) \wedge$ swrlb:lessThan(20,?temp $) \wedge$ setActive(LowTemperature,false) $\rightarrow$ SetActive (HighTemperature,false) ${ }^{\wedge}$ setActive(NormalTemperature,false) ${ }^{\wedge}$

SetActive(LowTemperature,true) ${ }^{\wedge}$ LocatedIn(HighTemperature,?X)

LocatedIn(Person,?x)^HeartRate(Person,?y)^^swrlb:greaterThan(60,?y)^swrlb:lessThan(100,?y)^setActive(PersonHasNormalHeartRate,fa $l s e) \rightarrow$ setActive (PersonHasNormalHeartRate,true) ${ }^{\wedge}$ setActive(PersonHasAbnormalHeartRate, false) ${ }^{\wedge}$ LocatedIn(PersonHasNormalHeartRat $e, ? x)$

The second category, however, aims to insert new knowledge to the ontology. For example:

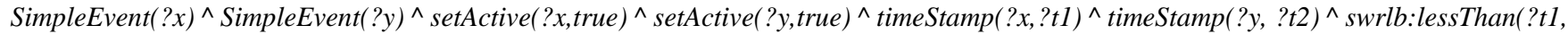
$? t 2) \rightarrow$ follows $(? y, ? x)$

i) Node identfication

On the other hand, the Bayesian Reasoner constitutes the second reasoning leve, formally probabilistic reasoning, to handle the problem of the uncertainty of context, which is unavoidable [7]. The BBN (Bayesian Belief Network) is a probabilistic graphical model that represents a set of random variables and their conditional independencies using a directed acyclic graph (DAG) [18]. Our approach to learn the BBN is a variation of the work presented in [12] but designed to be more suitable for SMILE's ontology model. The steps for this translation can be described as follows:

The variables of interest relevant to activity recognition are selected from ontology to establish the Bayesian network nodes. Thus, the classes SimpleEvent and Activity are selected.

The values which these nodes can take they are limited to are of Boolean type, since The Simple Event node in the Bayesian network are the values the property setActive in the ontology and the values of Activity node in the Bayesian network are the values of the property ActivityState.

\section{ii) Defining the BBN Structure}

Defining the structure of the Bayesian network means defining the links that connect the nodes to each other. Thus, if the relationship owl:DependsOn exists between two selected concepts in the ontology, then this relationship is transformed into a dependency arc between their corresponding Bayesian network nodes.

iii) $\quad$ BBN patameters

The BBN Parameters estimation are done via Likelihood estimation, it consists of finding the maximum likelihood of a specific BBN where is the most likely given the data, the result is what so-called CPT (Conditional Probability table) containing the Probabilities of each node given the configuration of parent values.

After the construction of the BBN, the probabilistic reasoning (inference) is done such that each activity has a specific probability knowing the specific simple events. The inference results are then saved in the ontology as follows:

- $\quad$ The value of the state with the highest probability is saved under the property "ActivityState" of the class "Activity"

- The value of the probability of the state is saved under the property "HasConfidenceLevel” of the class "Activity"

For instance, having an Emergency of type "HeartAttack" can take Boolean values. As placed by an expert, it depends on the following instances of class "SimpleEvent": "PersonIsFalling", "PersonHasAbnormalSweat", "PersonHasshortBreathe" etc... An illustration of the process of translation from the ontology to BBN is shown in Figure 5. In our example, however, the ontology the class "Emergency" (a subclass of "Activity") does not take any new values since the probability that the person has a heart attack actually knowing all parents is equal to $32.5 \%$.

Figure 5 Learning BBN from ontology 


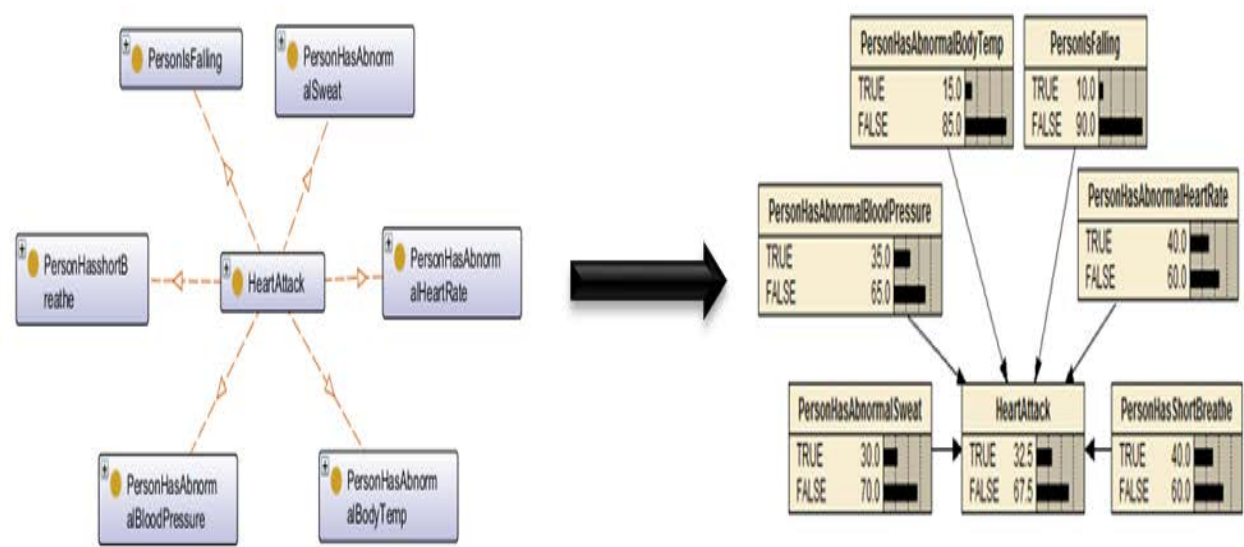

\subsection{Service Presentation layer}

The Service Presentation Layer (Figure 6) is responsible for the triggering health care services through the Service Execution Manager.

Figure 6 Service Presentation layer

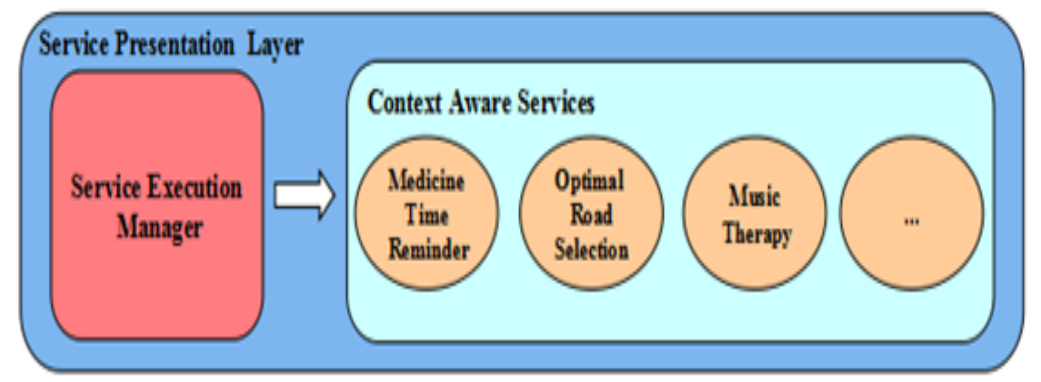

A. SMILE's services

The emergency handling services are designed to support an early detection of an emergency and a fast emergency response. While the emergency prevention services are designed, after a wide research in the field of heart-related emergencies, to create organize the patient's life style in a way that increases over all health and lowers the impact of any factor that causes heart problems. It is also noteworthy that the efficiency of emergency prevention services highly depends on the patient's commitment to the system instructions and advices.

Mainly our decision making tools are used: logic rules, CL (confidence Level), AHP (Analytic hierarchy process) and ID (influence diagram). Each of them suits a specific type of service. Table 1 briefly describes the main services of the system.

Table 1 Main services of the system

\begin{tabular}{|c|c|c|c|c|c|}
\hline $\begin{array}{l}\text { Functiona } \\
\text { lity }\end{array}$ & $\begin{array}{l}\text { Service } \\
\text { Name }\end{array}$ & Description & $\begin{array}{l}\text { Decisio } \\
\mathrm{n} \\
\text { Making } \\
\text { Tool }\end{array}$ & Notes & $\begin{array}{l}\text { Level of } \\
\text { sensitivit } \\
y\end{array}$ \\
\hline \multirow[t]{2}{*}{$\begin{array}{l}\text { Emergenc } \\
\text { y } \\
\text { Preventio } \\
n\end{array}$} & $\begin{array}{l}\text { Clothin } \\
g \quad \text { Tip } \\
\text { Service }\end{array}$ & $\begin{array}{l}\text { Informs the user to } \\
\text { wear suitable } \\
\text { clothes if the } \\
\text { weather is cold. }\end{array}$ & $\begin{array}{l}\text { Logic } \\
\text { Rules }\end{array}$ & $\begin{array}{l}\text { cold air temperatures have been } \\
\text { shown to alter heart rate and was } \\
\text { shown to be statistically related to } \\
\text { deaths from stroke and heart } \\
\text { attacks[16] }\end{array}$ & $\begin{array}{l}\text { Weakly } \\
\text { sensitive }\end{array}$ \\
\hline & $\begin{array}{l}\text { Music } \\
\text { Therap }\end{array}$ & $\begin{array}{lr}\text { Plays } & \text { relaxing } \\
\text { therapy } & \text { music }\end{array}$ & $\begin{array}{l}\text { Influen } \\
\text { ce }\end{array}$ & $\begin{array}{lcr}\text { Relaxing } & \text { music } & \text { reduces } \\
\text { sympathetic } & \text { nervous } & \text { system }\end{array}$ & Sensitive \\
\hline
\end{tabular}




\begin{tabular}{|c|c|c|c|c|c|}
\hline & $\begin{array}{l}y \\
\text { Service }\end{array}$ & $\begin{array}{l}\text { while the user is } \\
\text { sleeping } \\
\text { driving. }\end{array}$ & $\begin{array}{l}\text { Diagra } \\
\mathrm{m} \\
\text { And } \\
\text { Confid } \\
\text { ence } \\
\text { Level }\end{array}$ & $\begin{array}{l}\text { activity, decreases anxiety, blood } \\
\text { pressure, in addition to heart and } \\
\text { respiratory rate. In addition, music } \\
\text { therapy was proved to help in } \\
\text { reducing the autonomic nervous } \\
\text { system indicators of heart rate and } \\
\text { respiratory rate as well as elevated } \\
\text { state anxiety scores in patients who } \\
\text { have suffered from myocardial } \\
\text { infarction [17] }\end{array}$ & \\
\hline & $\begin{array}{l}\text { Exercis } \\
\text { ing } \\
\text { Music } \\
\text { Service }\end{array}$ & $\begin{array}{l}\text { executed when the } \\
\text { user is exercising } \\
\text { to facilitate } \\
\text { exercise } \\
\text { performance }\end{array}$ & $\begin{array}{l}\text { Confid } \\
\text { ence } \\
\text { Level }\end{array}$ & $\begin{array}{l}\text { Playing music while exercising aids } \\
\text { in reducing the feeling of fatigue } \\
\text { besides increasing levels of } \\
\text { psychological } \\
\text { physiological relaxation response } \\
\text { and improving in motor } \\
\text { coordination }\end{array}$ & $\begin{array}{l}\text { Weakly } \\
\text { Sensitive }\end{array}$ \\
\hline & $\begin{array}{l}\text { Exercis } \\
\text { ing } \\
\text { Assista } \\
\text { nt } \\
\text { Service }\end{array}$ & $\begin{array}{l}\text { Organize the user's } \\
\text { exercising routine } \\
\text { specifically } \\
\text { aerobic activities } \\
\text { by reminding the } \\
\text { user of exercising } \\
\text { times and duration } \\
\text { and playing } \\
\text { aerobic training } \\
\text { videos on the } \\
\text { user's TV. In } \\
\text { addition, } \\
\text { displays it } \\
\text { notification a } \\
\text { message when the } \\
\text { body parameters } \\
\text { measured by } \\
\text { sensors indicate } \\
\text { that the body is } \\
\text { tired and the user } \\
\text { should rest. }\end{array}$ & $\begin{array}{l}\text { Logic } \\
\text { Rules }\end{array}$ & 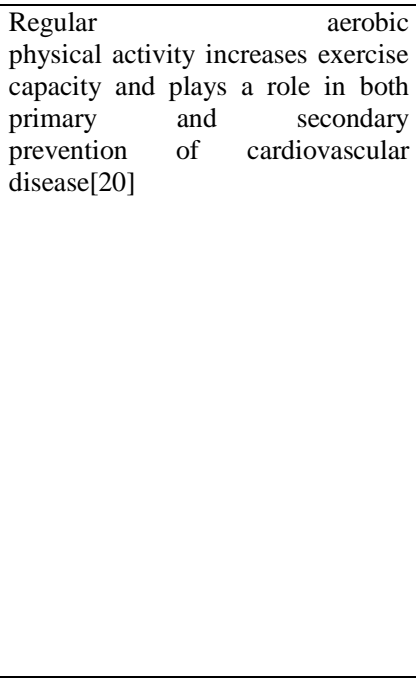 & $\begin{array}{l}\text { Weakly } \\
\text { Sensitive }\end{array}$ \\
\hline & $\begin{array}{l}\text { Food } \\
\text { Recom } \\
\text { mendat } \\
\text { ion } \\
\text { Service }\end{array}$ & $\begin{array}{l}\text { Gives food } \\
\text { recommendations } \\
\text { for each meal } \\
\text { including snacks } \\
\text { when the user } \\
\text { location is detected } \\
\text { to be at a restaurant } \\
\text { or at the kitchen } \\
\text { depending on the } \\
\text { time of the day. }\end{array}$ & $\begin{array}{l}\text { Logic } \\
\text { Rules }\end{array}$ & $\begin{array}{l}\text { Data used by these services are } \\
\text { placed by a dietitian every week } \\
\text { based on the user's blood sugar, } \\
\text { cholesterol levels and other physical } \\
\text { parameters. }\end{array}$ & $\begin{array}{l}\text { Slightly } \\
\text { Sensitive }\end{array}$ \\
\hline & $\begin{array}{l}\text { Shoppi } \\
\text { ng Lists } \\
\text { Display } \\
\text { Service } \\
\text {. }\end{array}$ & $\begin{array}{l}\text { Displays shopping } \\
\text { lists when the user } \\
\text { is at the shopping } \\
\text { center. }\end{array}$ & $\begin{array}{l}\text { Logic } \\
\text { Rules }\end{array}$ & $\begin{array}{l}\text { Shopping lists are also placed by a } \\
\text { dietitian. }\end{array}$ & $\begin{array}{l}\text { Slightly } \\
\text { Sensitive }\end{array}$ \\
\hline $\begin{array}{l}\text { Emergenc } \\
\mathrm{y} \\
\text { Handling }\end{array}$ & $\begin{array}{l}\text { Emerge } \\
\text { ncy } \\
\text { Notific } \\
\text { ation } \\
\text { Service }\end{array}$ & $\begin{array}{l}\text { In case an } \\
\text { emergency is } \\
\text { detected with high } \\
\text { probability, it } \\
\text { informs the nearest } \\
\text { ambulance and } \\
\text { hospital, the } \\
\text { message includes } \\
\text { the patient ID, the } \\
\text { emergency } \\
\text { location, and a list } \\
\text { of what medicines } \\
\text { the user is allergic } \\
\text { to beside the } \\
\text { probable type of }\end{array}$ & $\begin{array}{l}\text { Probabi } \\
\text { listic } \\
\text { Rules }\end{array}$ & & $\begin{array}{l}\text { Extremel } \\
\text { y } \\
\text { Sensitive }\end{array}$ \\
\hline
\end{tabular}




\begin{tabular}{|c|c|c|c|c|}
\hline & & $\begin{array}{l}\text { emergency. } \\
\text { Moreover, it } \\
\text { informs the closest } \\
\text { relative using an } \\
\text { SMS message with } \\
\text { the name and } \\
\text { address of the } \\
\text { hospital that the } \\
\text { user is taken to. In } \\
\text { case the } \\
\text { probability of the } \\
\text { emergency is not } \\
\text { too reliable then it } \\
\text { only informs a } \\
\text { relative to check } \\
\text { up on the patient. }\end{array}$ & & \\
\hline $\begin{array}{l}\text { Emergenc } \\
\text { y } \\
\text { Handling } \\
\text { and } \\
\text { emergenc } \\
\text { y } \\
\text { Preventio } \\
\text { n }\end{array}$ & $\begin{array}{l}\text { Optima } \\
\text { l Road } \\
\text { Selecti } \\
\text { on } \\
\text { Service }\end{array}$ & $\begin{array}{l}\text { It is mainly } \\
\text { executed in the } \\
\text { user's car and in } \\
\text { the ambulance. It } \\
\text { shows the } \\
\text { ambulance what is } \\
\text { the best road to } \\
\text { take to reach the } \\
\text { emergency } \\
\text { location in the least } \\
\text { possible time. } \\
\text { Moreover, it is } \\
\text { used to evaluate } \\
\text { the less congested } \\
\text { road which could } \\
\text { be taken to reach } \\
\text { the user's } \\
\text { destination in case } \\
\text { of driving in order } \\
\text { to avoid the stress } \\
\text { and tension caused } \\
\text { by being stuck in } \\
\text { traffic jams. In the } \\
\text { second case the } \\
\text { user enters the } \\
\text { destination } \\
\text { manually to the } \\
\text { system. }\end{array}$ & AHP & Sensitive \\
\hline
\end{tabular}

B. The decision making manger

The main decision making component of the system. As mentioned above it uses four tools for decision making.

i). Logic Rules: Used to trigger services that simply needs information about certain contextual parameters in the ontology. For example:

SetActive(TimeIsMorning,true)^^etActive(UserInKitchen,true)^Executed(BreakFastRecommendation,false) Executed(BreakFastRecommendation,true)

ii). Confidence Level: Used to trigger services that are executed upon realizing uncertain contextual parameters as the user activity. The decision making mechanism is based on the principal of confidence level (our variation of the percentage scale [13]. As shown in Figure. the probabilities that result from the Bayesian inference are regarded as levels of confidence. Services are divided into categories of sensitivity depending on the situation's ability of handling fault and errors. Each category has a specific CL that needs to be reached so the service can be executed. Extremely sensitive services need maximum CL, highly sensitive services need excellent CL, sensitive services need very good CL, slightly sensitive services need good CL and weakly sensitive need slightly good CL. Rules are written in a form that shows the required CL for each kind of services. For instance: ActivityState(Shopping,true)^HasConfidenceLevel(Shopping,?x)^swrlb:greaterThan(?x,30)^

Executed(DisplayShoppingList,false) $\rightarrow$ Executed(DisplayShoppingList,true) 
Figure 7 Confidence level Axis

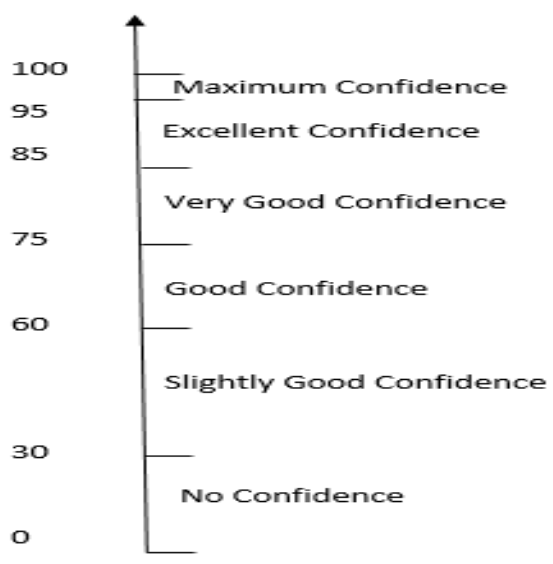

iii) AHP: a multi-criteria decision making tool which represents a methodology to calibrate the numeric scale for the measurement of quantitative as well qualitative performances [14] . It is used mainly by the system for optimal road selection. First, the selection criteria are identified as: distance, GPS info, historical info, traffic phone application info and type of road. Roads alternatives are firstly compared to each criterion and then compared with respect to each other to form pair wise comparison matrices. Next, the evaluation of each road to decide what is the best road alternative is done using two steps. The first step is normalizing vectors by summing values in each column of the pair wise comparison matrices, then dividing each value in a column by its corresponding column sum to normalize preference values then calculating the average of the values in each row. The second step is developing of the overall ranking to decide which one is the most important. Finally, the road with the highest score is displayed on the ambulance screen/or the patient's car screen. A More detailed illustration can be found in our previous work [10]. Figure 8 shows the interface of the application we developed.

Figure 8 Optimal road selection system interface

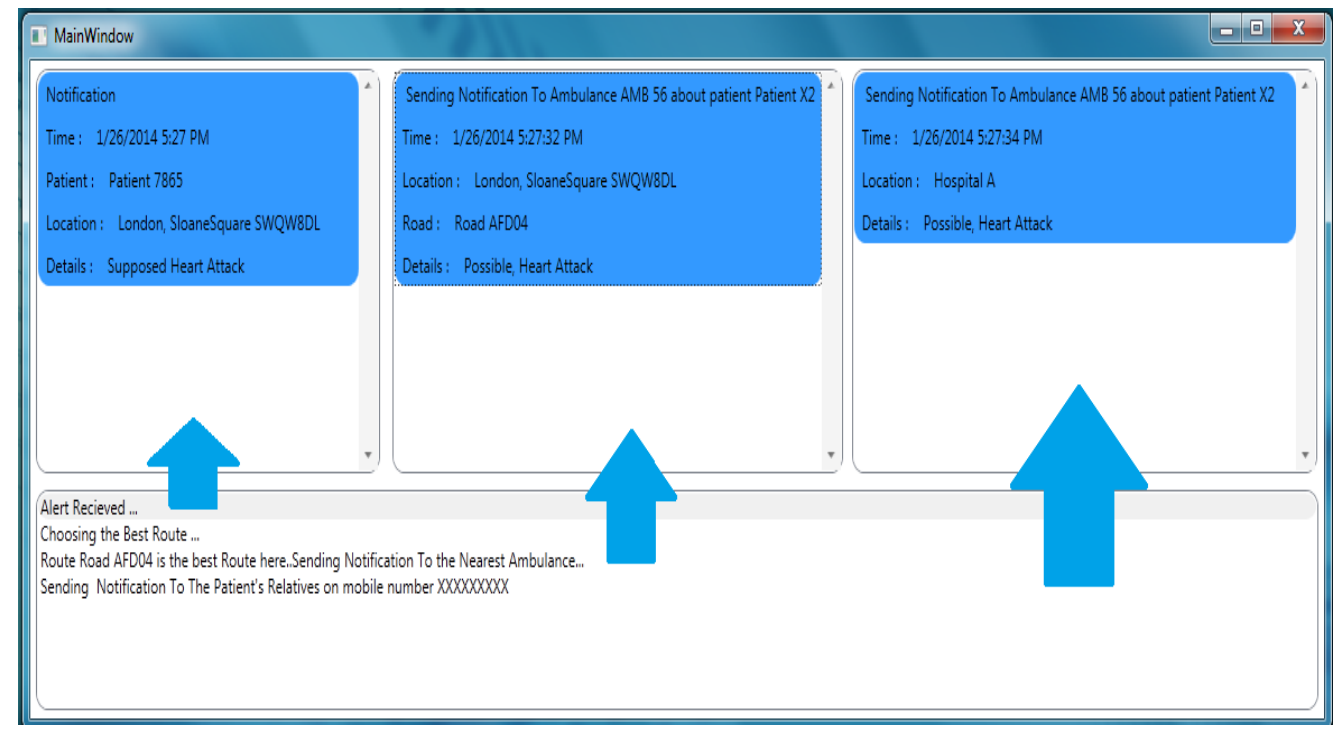

iv). Influence Diagram: Music therapy is not a random service. The decision of what music tracks should be played in the music therapy service is based on the user emotional state and the mood improvement recorded after playing a certain track during a specific state. To aid in the decision making process we use ID (Influence Diagram). An ID [15] is a BBN augmented with decision nodes representing decision alternatives and utility nodes, which assign a utility value to each state of the world. For deciding what music track should be played we build an influence diagram with 3 nodes: EmotionalState (uncertainty node), 
PlayMusic (decision node) and the MoodImprovement (utility node). We apply the same parameter learning strategy used for BN for learning the parameters of the music selection utility diagram. For example, the music preferences of each emotional state are as follows: track 1 for happy, track 2 for sad and track 3 for neutral. The ID after inference is shown in Figure 9. where the patient is $60 \%$ happy and track 2 is the choice with the highest utility.

Figure 9 Best music track selection using ID

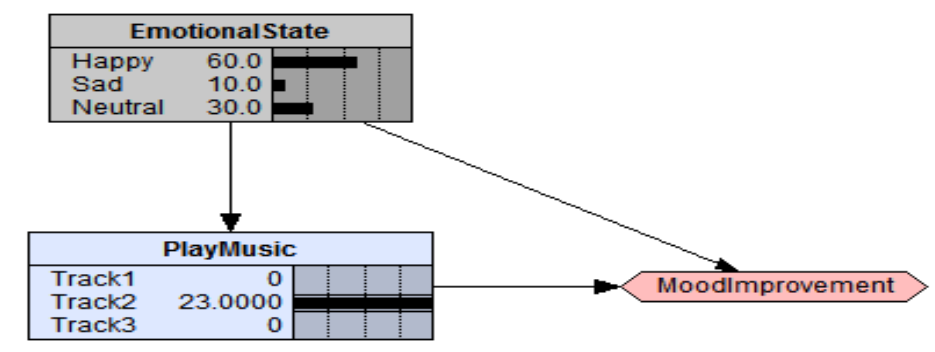

\section{Conclusion}

This work introduced SMILE, Smart Monitoring Intelligent Learning Engine, a context aware system that presents smart remote health care services for patients subjected to severe emergencies, enabling them to continue their daily life routine while being monitored and protected. Our study was mainly focused on heart patients.

The novelty of this approach lied in the design of the main system's functionalities integrating emergency handling and emergency prevention services together, where the services are not only focused on detecting an emergency situation in the least possible time, but also aim to prevent an emergency from happening in the first place through lowering the impact of its possible causes. To succeed our objectives, a layered middleware architecture was proposed for supporting context adaptation with the main functionalities of data acquisition, storage, processing and decision making.

We also exploited the potentials of ontologies for context modeling to give computational entities a common set of concepts about interacting with one another and maintain the coherence of the knowledge structure.

For realizing the Intelligence of sMILE the system functionalities included two reasoning levels used to overcome the challenging task of exploiting the true meaning context data, considering the demand of instant responses of the system any change in its context besides the imperfect and uncertain nature of context data. The first level is ontology reasoning that produces additional knowledge, in particular Simple Events. The second level applies machine learning techniques, specifically BBN, to infer the probabilities of activities knowing simple events generated by the first reasoning level. The advantages of Bayesian Reasoning is mainly in dealing with the uncertainty aspect of the system through supporting the inference of various types of activities based on the knowledge already saved in the database beside producing results specific for each user enabling SMILE to learn its users and their context. At the end, the activity with the highest probability is sent to the database for further processing associated with the value of the probability or the confidence level. The confidence level is later used to aid the decision making process. Moreover, for having more accurate decisions, influence diagrams and AHP multi-criteria decision making model are used along with probabilistic rules based on confidence levels and basic semantic rules. Influence diagram supports decision making based on expected utility of each decision, while AHP aids in making decisions which are based on multiple criteria.

The next phases of this work include experimenting using real data and the complete implementation of sMILE system. Another direction for our future work is dealing with a main limitation of the system as recognizing multiple activities and supporting using Dynamic Bayesian Networks to predict the activities of the user including abnormal activities (as suffering from an emergency), thus presenting more intelligent, reliable and efficient services. 


\section{References}

1. Vilahur, Gemma, et al. "Perspectives: The burden of cardiovascular risk factors and coronary heart disease in Europe and worldwide." European heart journal16.suppl_A (2014): A7-A11

2. I. Korhonen, P. Paavilainen, A. Särelä, "Application of ubiquitous computing technologies for support of independent living of the elderly in real life settings," in The 2nd International Workshop on Ubiquitous Computing for Pervasive Healthcare Applications, Seattle, Washington, 2003.

3. Paganelli, Federica, and D. Giuli, "An ontology-based system for context-aware and configurable services to support home-based continuous care," Information Technology in Biomedicine, IEEE Transactions, vol. 15, no. 2, pp. 324-333, 2011.

4. S. Helal, C. Giraldo, Y. Kaddoura, C. LEE, H. El Zabadani, W. Mann, "Smart phone based cognitive assistant," in The 2nd International Workshop on Ubiquitous Computing for Pervasive Healthcare Applications, Seattle, Washington, 2003.

5. A. Mihailidis, B. Carmichael, J. Boger, G. Fernie, "An intelligent environment to support aging-in-place, safety, and independence of older adults with dementia," in The 2nd International Workshop on Ubiquitous Computing for Pervasive Healthcare Applications, Seattle, Washington, 2003.

6. M. Baldauf, S. Dustdar, "A Survey on Context-Aware Systems", in the international journal of Ad Hoc and Ubiquitous Computing, Vol 2, No 4, 2007

7. T. Strang, C. Linnhoff-Popien, "A context modeling survey," in First International Workshop on Advanced Context Modeling, Reasoning and Management, UbiCom, Nottingham, UK, 2004.

8. Z. Ding, Y. Peng. "A Probabilistic Extension to Ontology Language OWL", In Proceedings of the 37th Hawaii International Conference on System Sciences, Hawaii, January 2004.

9. G. D. Abowd, A. K. Dey, P. J. Brown, N. Davies, M. Smith, and P. Steggles, "Towards a better understanding of context and context-awareness," in Proceedings of the 1st international symposium on Handheld and Ubiquitous Computing, ser. HUC '99. London, UK: Springer-Verlag, 1999, pp. 304-307

10. Hamid Mcheik, Malak Khreis, Hala Swaiden, Mohammad AL-kalla, “CARE: Context Aware Reliable Engine Health and Traffic Monitoring System”. In The sixteenth International Conference On Modeling and Simulation, UKSIM, IEEE, Cambridge, 2014. 11. I. Horrocks, PF Patel-Schneider, H. Boley, S. Tabet, B. Grosof, M. Dean, "SWRL: A semantic web rule language combining OWL and RuleML," W3C Member submission, pp. 21-79, 2004.

12. Devitt, Ann, Boris Danev, and Katarina Matusikova. "Constructing Bayesian networks automatically using ontologies." ,2006.

13. I.Zaarour, J. Labiche, and D. Meillier, "Classification de l’Écriture des Groupes d`Enfants Typiques", in 3rd International Conference: EMedical Systems, Vol. 24, pp. 1214, 2010.])

14. T. Saaty, The Analytic Hierarchy Process, McGrawHill, 1980

15. R. Qi, NL Zhang, D. Poole, "Solving asymmetric decision problems with influence diagrams," in Proceedings of the Tenth Conference on Uncertainty in Artificial Intelligence (UAI-94), San Francisco, 1994. 
SMILE: Smart Monitoring Intelligent Learning engine

16. A. Baker-Blocker, "Winter weather and cardiovascular mortality in Minneapolis-St. Paul." American journal of public health 72.3: 261-265, 1982.

17. khalfa S, Bella SD, Roy M, Peretz I, Lupien SJ. Effects of relaxing music on salivary cortisol level after psychological stress. Ann N Y Acad Sci. Nov;999:374-6, 2003].

18. J. Pearl, "Reverend Bayes on Inference Engines: A Distributed Hierarchical Approach," AAAI, pp. 133 - 136, 1982.

19. T. R. Gruber, "Towards Principles for the Design of Ontologies Used for Knowledge Sharing”, International Journal Human-Computer Studies, vol. 43, Issues 5-6, pp. 907-928, 1995.

20. Fletcher, Gerald F., et al. "Statement on exercise: Benefits and recommendations for physical activity programs for all Americans a statement for health professionals by the committee on exercise and cardiac rehabilitation of the council on clinical cardiology, American heart association." Circulation94.4 (1996): 857-862. 